\title{
TECNOGRAN: TODO PISO SERÁ PALCO. TODA PAREDE, MURAL. E A CIDADE INTEIRA, POESIA.
}

\author{
Danielle Denes dos Santos Carstens* \\ danielled.carstens@gmail.com \\ Ticiana Braga De Vincenzi* \\ ticivin@hotmail.com
}
Bruno Henrique Rocha Fernandes*
bruno@up.edu.br
Franciani Fernandes Galvão**
comexfran@hotmail.com

*Universidade Positivo **Universidade Estadual de Maringá - Maringá, PR / Brasil

http://dx.doi.org/10.1590/1413-2311.16815.60638

Recebido em 04/12/2015

Aprovado em 22/08/2016

Disponibilizado em 31/01/2017

Avaliado pelo sistema "double blind review"

Revista Eletrônica de Administração

Editora-chefe: Aurora Zen

ISSN 1413-2311 (versão "on line")

Editada pela Escola de Administração da Universidade Federal do Rio Grande do Sul.

Periodicidade: Quadrimestral

Sistema requerido: Adobe Acrobat Reader

\section{RESUMO}

Este caso apresenta a Tecnogran, empresa paranaense de revestimentos de alto tráfego atuante no segmento de pisos para supermercados, shopping centers, áreas externas, obras públicas e de acessibilidade. O caso descreve o histórico, as características da organização e do setor, abordando impasses enfrentados pela Tecnogran: pressões por preço e demandas de mercado. A empresa é líder no mercado nacional e, apesar disso, encontra dilemas ao buscar se consolidar como inovadora frente a seus concorrentes. O caso é analisado sob as perspectivas das teorias: Estratégias Genéricas e Vantagem Competitiva Ambiental; Teoria Baseada em Recursos; e Teoria de Recursos, Processos e Valores na Inovação. O caso apresenta também as respostas da empresa: inovações em produtos e serviços, e alterações em processos produtivos para manutenção de sua liderança no mercado nacional. As informações para a elaboração do caso foram obtidas por entrevistas semiestruturadas com os gestores da Tecnogran e por dados secundários, tais como publicações, documentos da empresa e sites. Este caso de ensino poderá ser utilizado nas disciplinas de Administração Estratégica, Gestão da Inovação, Marketing e disciplinas correlatas, em cursos de graduação e pós-graduação com foco em negócios de empresas. Os principais objetivos educacionais são: sensibilizar alunos para perceber as estratégias empresariais; analisar os modelos de gestão em busca de vantagem competitiva; identificar modelos estratégicos organizacionais; assinalar a relação 
entre competências organizacionais e vantagem competitiva sustentável; e compreender a importância e os desafios da inovação para as organizações.

Palavras-chave: Inovação; Estratégias Genéricas; Vantagem Competitiva; Teoria Baseada em Recursos; Teoria de Recursos, Processos e Valores.

\title{
TECNOGRAN: EVERY FLOOR WILL BE A STAGE; WALLS WILL BE MURALS; AND THE ENTIRE TOWN, POETRY.
}

\begin{abstract}
This case presents Tecnogran, a Brazilian producer of high traffic floorings for supermarkets, shopping malls, outdoors, public works and accessibility works. The case describes the history and characteristics of the organization, addressing impasses faced by Tecnogran: price pressures and market demands. Tecnogran is the domestic market leader, and yet faces dilemmas to endorse itself as an innovative company. The case analysis is based on the following theories: Generic Strategies and Competitive Advantage; Resource-Based Theory; and Resources, Processes and Values Theory. The case also shows the company's response: products and services innovations, and production processes changes to maintain the domestic market leadership. The data for the preparation of this teaching case were obtained through semi-structured interviews with Tecnogran managers and through secondary data, such as business documents, internal reports, publications and websites. This teaching case can be used in disciplines related to strategic management, innovation studies, marketing and other related disciplines in undergraduate and post-graduation management courses. The main learning objectives are: to help students comprehend business strategies; to analyze competitive advantage management models; to identify organizational strategic models; to verify the relationship between organizational competencies and sustainable competitive advantage; and to understand the importance and challenges of innovation for organizations.
\end{abstract}

Keywords: Innovation; Generic Strategies; Competitive Advantage; Resource-Based Theory; Resources, Processes, and Values Theory.

\section{TECNOGRAN: PISOS SERÁN ESCENARIOS; PAREDES SERÁN MURALES; Y LA CIUDAD ENTERA, POESÍA.}

\begin{abstract}
RESUMEN
Este caso presenta Tecnogran, una empresa brasileña de revestimientos para alto tránsito que actúa en el segmento de pisos para supermercados, centros comerciales, áreas externas, obras públicas y de acceso. El caso describe la historia y las características organizacionales de la industria, frente a los impasses que enfrenta Tecnogran: presión de precios y demandas del mercado. La compañía es líder en el mercado nacional, pero encuentra dilemas en la búsqueda por consolidarse como innovadora en relación a sus competidores. El caso, que se analiza desde las perspectivas teóricas de las Estrategias Genéricas y Ventaja Competitiva; de la Teoría Basada en Recursos y Teoría de los Recursos, Procesos y Valores, también muestra la respuesta de la empresa: innovaciones en productos y servicios y cambios en los procesos de producción para mantener su liderazgo en el mercado nacional. Las informaciones para la preparación del caso se obtuvieron mediante entrevistas semiestructuradas con los directores
\end{abstract}


de Tecnogran y datos secundarios, tales como publicaciones, documentos comerciales y sitios. Este caso se puede utilizar en la enseñanza de las disciplinas de Gestión Estratégica, Gestión de la Innovación, Marketing y disciplinas afines en los programas de pregrado y postgrado enfocados en negocios corporativos. Las principales metas educativas son: sensibilizar a los estudiantes frente a las estrategias de negocio; analizar los modelos de gestión en la búsqueda por la ventaja competitiva; identificar los modelos estratégicos de la organización; señalar la relación entre competencias organizacionales y ventaja competitiva sostenible y entender la importancia y los desafíos de la innovación para las organizaciones.

Palabras Clave: Innovación; Estrategias Genéricas; Ventaja Competitiva; Teoría Basada en Recursos; Teoría de los Recursos, Procesos y Valores.

\section{INTRODUÇÃO}

Numa manhã chuvosa de outubro de 2014 em Curitiba, Mariana, sócia-proprietária e diretora administrativa da Tecnogran, dirigia seu carro enquanto preocupava-se com uma difícil decisão sobre o principal produto de sua empresa, o piso vibro prensado para ambientes de alto tráfego. Os clientes solicitavam mais opções de produtos, tanto em novos formatos quanto em maior variedade de texturas e cores.

Atuando há muitos anos no setor, a Tecnogran fabricava pisos no tamanho $40 \mathrm{cmX} 40 \mathrm{~cm}$. Porém os compradores, influenciados por seus arquitetos, demandavam cada vez mais tamanhos diferenciados, tais como $40 \mathrm{cmX} 60 \mathrm{~cm}, 20 \mathrm{cmX} 60 \mathrm{~cm}, 80 \mathrm{cmX} 80 \mathrm{~cm}$, que a empresa não produzia devido a limitações em seus equipamentos. Seria necessário investir em máquinas e treinamento de mão de obra para fabricar e aplicar o produto conforme as novas especificações e necessidades dos consumidores.

Mariana receava que essas mudanças aumentassem os custos de operação. Embora não concorresse por preço, a empresa sentia necessidade de, mantendo o padrão de qualidade, reduzir os custos e aumentar a produtividade para ser mais competitiva no mercado. Desde 2013 a Tecnogran havia implantado várias ações nesse sentido. Todavia, os gestores temiam que, ao investir em novos formatos, a empresa arriscaria o esforço empreendido até então.

No mesmo instante, em outro ponto da cidade, Antônio, gerente comercial da empresa, chegava a uma reunião com seu maior cliente, e refletia sobre a possibilidade de oferecer-lhe uma solução de tratamento de piso desenvolvida pela Tecnogran ainda em teste. O cliente, uma grande rede nacional de supermercados, reclamava dos custos e da dificuldade de manutenção dos produtos oferecidos pela Tecnogran. Esse problema é uma característica do piso vibro prensado, independentemente do fabricante. Ciente disso, a Tecnogran desenvolveu, junto com uma indústria química parceira, um método de finalização do produto 
que protege o piso e minimiza a necessidade de manutenção. Porém, por ser novidade, estava sendo testado somente em alguns clientes, pois a empresa não queria colocar em risco a imagem do seu serviço. Antônio questionava-se se deveria oferecer essa solução ao cliente.

\section{HISTÓRICO}

A Tecnogran foi criada a partir de uma oportunidade de mercado. A rede de supermercados Carrefour, ao se instalar no Brasil em meados dos anos 70, demandava por pisos de alto tráfego para suas lojas. Os amigos Roberto e José então iniciaram uma sociedade e fundaram a Tecnogran, comprando e revendendo piso vibro prensado de outro fornecedor para vender ao Carrefour. A intenção dos sócios era criar a marca para atender essa rede de supermercados. Foi a partir daí que outras redes seguiram a mesma tendência em pisos, utilizando o "Marcopiso", nome pelo qual o piso tipo vibro prensado é conhecido no Brasil. Isso porque um dos primeiros fabricantes no país assim denominou esse tipo de revestimento.

Tempos depois, em 1989, os sócios construíram uma máquina própria para fabricar o produto, que apelidaram de "Terezona", mas era manual e de baixa capacidade de fabricação. Surgia, assim, a fábrica de pisos e revestimentos Tecnogran. Posteriormente compraram um equipamento com tecnologia italiana (referência mundial em produção desse tipo de piso) para prensar o piso, permitindo mais capacidade de produção e qualidade para os produtos.

Desde então, a empresa ampliou sua gama de clientes no segmento e hoje atende grande parte das redes de supermercados, sendo a maior empresa fabricante de piso vibro prensado do Brasil. Também expandiu seu foco de atuação para shoppings centers, tornando-se fornecedora das principais redes do país.

$\mathrm{Na}$ fundação, Roberto assumiu o departamento comercial, José a operação industrial e Vinícius, filho de Roberto, a direção administrativa. José, em 1994, vendeu sua parte para Roberto, e hoje a empresa familiar está na segunda geração, com dois irmãos conduzindo a companhia: Vinícius na presidência e Mariana na direção administrativa.

Mariana, formada em psicologia, trabalha na Tecnogran desde 2010, tendo assumido a área financeira. Quando ingressou na empresa, seu pai ainda era vivo (faleceu em 2011), e seu marido, Thiago, trabalhava como gerente industrial. Neste mesmo ano fundaram a TCO Construtora, na qual Thiago assumiu a diretoria de operações. A partir daí Mariana acumulou a direção administrativa e fabril até contratarem um gerente industrial em 2014. 
Já Antônio ingressou na Tecnogran em junho de 1999 na área administrativo-financeira, cuidando de contas a pagar e a receber. Passou mais tarde a gerente de contratos, fazendo a interface entre empresa e cliente final, bem como administrando contratos em execução com vários clientes e construtoras. Por fim, foi para área comercial, e hoje é gerente comercial da empresa em nível nacional.

\section{A EMPRESA}

O grupo Tecnogran é formado por 3 empresas: a Tecnogran Revestimentos (www.tecnogran.com.br/), a TCO (Tecnogran Construtora de Obras) Construtora (www.tcoconstrutora.com.br/) e a Terrazzo. No mercado desde 1989, a Tecnogran Revestimentos é hoje a maior indústria de pisos pré-moldados de alta resistência do Brasil, com mais de 8 milhões de $\mathrm{m}^{2}$ de pisos aplicados na América Latina, África e Oceania. Possui cerca de 70 colaboradores diretos atuando na produção de placas cimentícias vibro prensadas de alto tráfego. Os revestimentos da Tecnogran são aplicados em shoppings centers, supermercados, obras de acessibilidade e obras públicas.

A fábrica utiliza mão de obra especializada na produção. Tanto colaboradores na manutenção da planta quanto supervisores e operadores de prensa têm tempo médio de 17 anos de empresa, inclusive sendo muitos da mesma família e vivendo no entorno da fábrica. A empresa entende que o conhecimento e a proximidade dos colaboradores acentuam o comprometimento e atuação colaborativa para prevenir problemas no processo de fabricação.

A TCO Construtora trabalha em projetos de colocação e execução dentro das principais obras da Tecnogran, se diferenciando por contar com mão de obra especializada na aplicação desse tipo de piso. Ao realizar o orçamento dos pisos, a área comercial da Tecnogran Revestimentos sugere que a colocação seja executada pela TCO, salientando os benefícios de utilizar os serviços diferenciais da empresa, porém deixando essa decisão para o cliente. Já a Terrazzo disponibiliza a linha de produtos de tratamento e manutenção de pisos, como, por exemplo, selador (para proteger o piso) e rejuntes.

Antônio acredita que os diferenciais do grupo são: seu acervo de grandes obras, o compromisso com o padrão de qualidade e o relacionamento com os clientes. Buscando expandir a base de consumidores, desde 2011 a empresa vem diversificando sua atuação. Um dos focos foi contemplar o público residencial, no qual já aplicou seu produto em obras como condomínios, garagens, quadras esportivas e áreas de lazer. Como estratégia para ampliar sua 
atuação junto a esse segmento, em 2014 a Tecnogran participou da Casa Cor Paraná (exposição de arquitetura e decoração), em um espaço que foi premiado na mostra.

Antônio entende que a diversificação de mercado é algo fundamental para a empresa expandir suas fronteiras. "Daí a importância do departamento comercial abrir novos mercados e ser bastante ativo, sempre trazendo clientes para diluir custo fixo entre as obras da empresa”, declara o gerente. Como nem sempre a TCO dá conta de toda a demanda, a Tecnogran possui parceria com empresas com mão de obra qualificada credenciadas para também executar o serviço de aplicação do piso.

No processo decisório sobre a compra de produtos da empresa, a tomada de decisão varia de acordo com o segmento de atuação e do porte do cliente. Por exemplo, no segmento de supermercados, quem decide a compra em um pequeno varejo é o proprietário do supermercado; porém, nas grandes redes, a decisão acontece no setor de compras. No segmento de shopping centers, quem decide são arquitetos das empreiteiras das obras; e no segmento de residências, o agente decisor é o proprietário, que é muitas vezes direcionado pelo seu arquiteto. Já em obras públicas, a compra passa por processo de licitação.

Essa informação sobre quem são os diferentes agentes decisores de compra do produto é fundamental para que a Tecnogran direcione seus esforços de comunicação publicitária e linguagem organizacional. Assim, a empresa desenvolveu catálogos segmentados: para supermercados, shopping centers, residências e obras públicas. Os catálogos apresentam fotos de ambientes, comunicação dirigida e produtos aplicados em cada caso.

\section{INSUMOS E RESÍDUOS}

A principal matéria-prima do piso vibro prensado é a granilha dolomítica, um tipo de calcário moído. É difícil obter uma granilha pura, totalmente branca, pois, por ser origem mineral, pode ter veios de cores diferentes. Além disso, quanto mais impurezas na matériaprima, mais perdas ocorrem na produção. Mariana relata que "o mercado está cada vez mais exigente, não aceitando diferenças de tonalidade no piso”, sendo o piso branco, inclusive, uma requisição dos arquitetos devido ao status de sofisticação na arquitetura contemporânea.

Para atender às demandas de mercado e garantir a qualidade, a Tecnogran optou por ter um único fornecedor de matéria-prima. Esse fornecedor, a mineradora Pedra Boa (nome fictício), fica no município de Rio Branco do Sul, região metropolitana de Curitiba, a $40 \mathrm{~km}$ de distância da Tecnogran. A empresa entende que matéria-prima de qualidade é item 
fundamental para a uniformidade do produto, e, pelo grau de pureza requerido, é um recurso escasso. Por este motivo, em 2014, a Tecnogran adquiriu uma pedreira própria com pedras puras, entregando a exploração para essa mineradora parceira.

Outra matéria-prima que é base na fabricação dos pisos é o cimento branco. A região onde a Tecnogran está sediada conta com um dos maiores polos cimentícios do Brasil. Isso é importante para a empresa, pois a proximidade e a agilidade no abastecimento de matériasprimas são fatores críticos de sucesso, devido ao alto custo de transporte desses insumos.

Quanto ao refugo, o processo de fabricação dos pisos gera, como principal excedente, uma mistura cimentícia pastosa. Para evitar impactos ambientais negativos, a Tecnogran contrata os serviços de uma empresa especializada na correta destinação desses resíduos.

\section{PRODUTOS E SERVIÇOS}

Mariana comenta que a Tecnogran vende não um produto, mas um sistema: "o sistema é o piso acabado. O cliente deseja uma solução pronta para revestimento. Os diferenciais da Tecnogran perante os concorrentes são a mão de obra especializada e a logística”.

No processo logístico, o piso é enviado para o cliente via transporte terrestre. A Tecnogran possui parceria com transportadoras que levam o piso a todos os locais do país. Porém, como se trata de produto pesado, o custo do frete acaba por encarecer a venda e dificultar a negociação do produto. Em alguns casos, para grandes distâncias e quantidades, a empresa utiliza o transporte de cabotagem para entrega do produto.

Em 15 dias, quando o piso chega à obra, a equipe já está mobilizada para começar a colocação. A Tecnogran entrega o piso colocado, encerado e pronto para o cliente abrir seu estabelecimento. Como diferencial, o sistema da Tecnogran permite acompanhar a obra, sem prejuízos ao cronograma estabelecido pelo contratante. Muitas vezes o cliente quer construir em 40 dias um supermercado de $2.000 \mathrm{~m}^{2}$ ou mais. A empresa consegue colocar o piso mesmo antes da construção do telhado, possibilitando a continuação da obra. Mariana ressalta que "tempo é dinheiro, principalmente no porte das obras que a Tecnogran atende".

Em obras como as de shopping centers, onde há paginação de piso que contempla não só o piso vibro prensado, mas outros materiais como granito, porcelanato e madeira, a construtora TCO consegue fazer a instalação integralmente. Se o cliente optar por contratar a empresa para esse serviço, basta fornecer os demais pisos necessários para a instalação. Dessa 
forma, um único empreiteiro instala todo piso, evitando que o cliente gerencie diversos aplicadores para diferentes materiais e que um aplicador venha a avariar o material do outro.

Para garantir a precisão no serviço, a Tecnogran conta com uma arquiteta e um setor técnico que estuda a planta para adequar a quantidade de piso a ser utilizado e a perda prevista. Também dispõe de um setor de qualidade que fiscaliza a obra, para garantir o padrão estabelecido pela empresa, pois o "cliente pode comprar apenas o piso da Tecnogran e providenciar por conta própria a aplicação. Mas, quando vendemos o produto associado à mão de obra, garantimos os dois, o que dá ao cliente mais tranquilidade”, afirma Antônio.

Além do revestimento de ambientes internos, que é o carro-chefe da empresa, a Tecnogran produz pisos para áreas externas com grande resistência a peso e tráfego, sendo superiores ao tipo paver e ao ladrilho hidráulico. A aplicação do piso externo é bem mais simples, pois prescinde do processo de finalização. A empresa remete, junto com o produto, um manual de qualidade com especificações para instalação. Contudo, em obras maiores, a Tecnogran envia um funcionário do departamento de qualidade para orientar o cliente, principalmente na aplicação e limpeza do rejunte.

Como inovação própria, há 5 anos a empresa desenvolveu o piso drenante, que permite a passagem de mais de $95 \%$ da água, garantindo obras sustentáveis e evitando a incidência de enchentes. Este produto não necessita de contrapiso e pode ser assentado diretamente no solo, desde que a área esteja nivelada. Ele é considerado ecológico por sua capacidade de absorção, sendo demanda crescente entre as prefeituras do Brasil e tendência em obras públicas.

\section{O MERCADO}

O revestimento vibro prensado atende um nicho de mercado: o produto é uma alternativa para opções mais conhecidas, tais como pisos de pedras naturais (como granito e mármore), porcelanatos e pisos cerâmicos (Figura 1). Não existem organizações com atuação global no segmento: mesmo empresas de grande porte atuam regionalmente e dentro de seus respectivos países. O peso do produto inviabiliza a venda para locais distantes, pois o transporte, seja terrestre ou por cabotagem, encarece e muitas vezes inviabiliza o negócio. A proximidade de matéria-prima é também um fator de influência. 


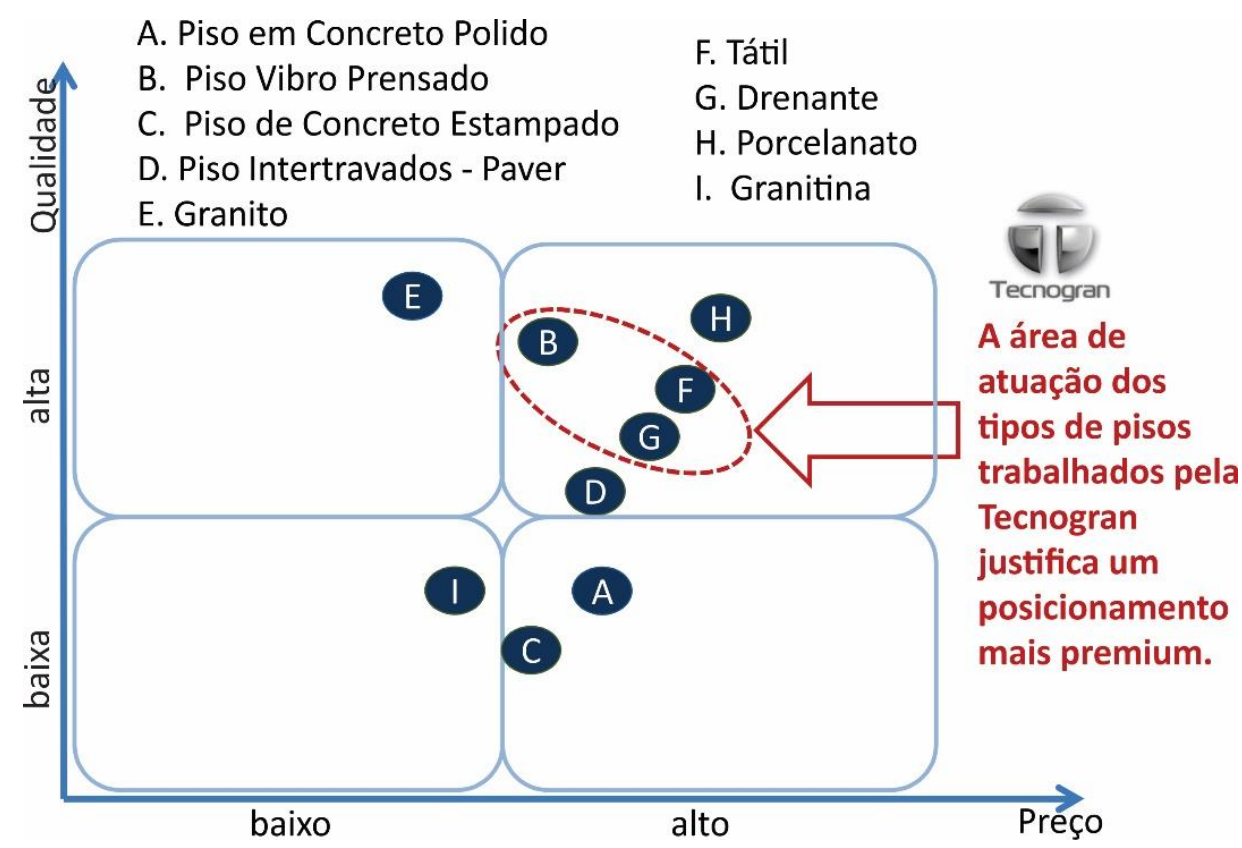

Figura 1 - Mapa de tipos de pisos - Contexto na Tecnogran Fonte: Dados fornecidos pela empresa

Os concorrentes diretos da Tecnogran em pisos de alto tráfego no Brasil (Figura 2) são: Unipiso (RJ), Goiarte (GO), Segato (MG), Ivaí Pisos (PR) e Basalto São Cristóvão (RS).

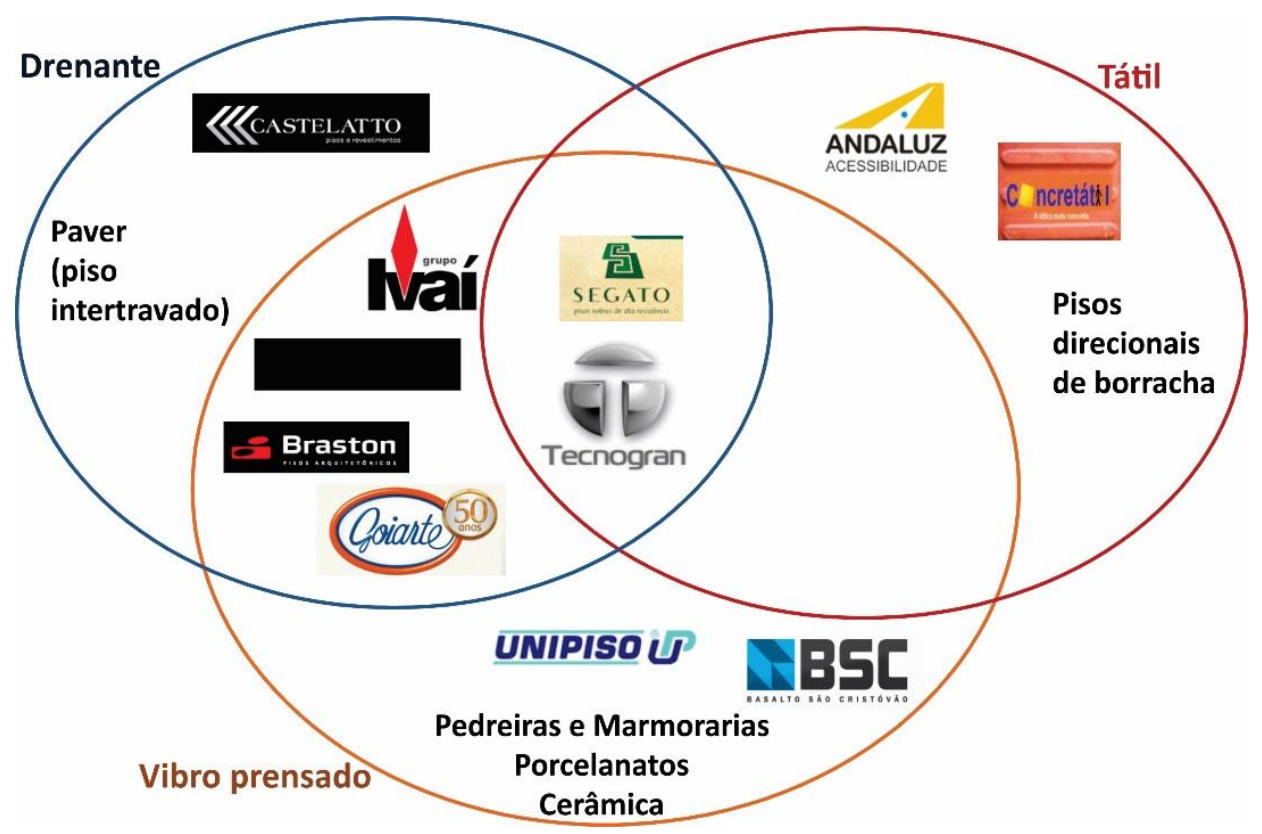

Figura 2 - Mapa de concorrentes por segmento Fonte: Dados fornecidos pela empresa

Nos demais tipos de revestimentos (Figura 2) atuam outros concorrentes: Braston e Castellatto (ambas de SP) - pisos drenantes; Dacapo - pisos (MG); além de pedreiras, marmorarias e fabricantes de porcelanatos e cerâmicas. As maiores empresas nessa atividade mantêm contato frequente para trocar ideias, principalmente sobre qualidade, produtos e 
fornecedores. Uma vez que o mercado é restrito, as empresas se preocupam em preservar a categoria do produto.

Os concorrentes da Tecnogran têm o mesmo produto e qualidade, mas não oferecem serviços de aplicação do revestimento, apenas indicam empresas terceirizadas. Portanto, a diferenciação da Tecnogran está na prestação do serviço. Como o piso não sai totalmente acabado de fábrica, apenas pré-polido, se não houver uma prestação de serviço adequada, isto é, colocação, polimento e finalização, todo o produto pode ser comprometido. Antônio observa que, em relação aos concorrentes diretos, "as vantagens da Tecnogran são que ela está há bastante tempo no mercado, tem nome forte e é reconhecida pela sua expertise, capacidade produtiva, e por agregar ao produto mão de obra especializada".

\section{DESAFIOS}

Para garantir o seu diferencial, ou seja, a solução pronta de piso para o cliente, a Tecnogran precisa ter alta capacidade de investimento. Os custos para manter uma empresa de mão de obra especializada como a TCO são elevados, já que o quadro de pessoal deve estar sempre completo para atender às obras no prazo que os clientes desejam. E cabe então à empresa bancar tais custos quando não há obras para atuar.

Por manter essa estrutura e por fornecer uma solução completa de aplicação e manutenção de pisos, a Tecnogran não compete em preço: seu posicionamento é de agregar valor ao serviço. Todavia, com a concorrência cada vez mais acirrada, a empresa sentiu a necessidade de reduzir os custos para obter preços mais competitivos. Em 2013 iniciou um trabalho na produtividade da fábrica para aumentar a produção e reduzir o desperdício, buscando manter a qualidade. Foram implantados controles de gestão à vista para que encarregados e operadores possam acompanhar a produção de cada máquina por hora.

Para enfrentar os desafios da empresa, a Tecnogran investiu na contratação de duas consultorias, uma administrativo-financeira e uma na área comercial, para otimizar os trabalhos e reduzir os custos de produção e de gestão. Também contratou um gerente industrial com ampla experiência em processos fabris, ainda que sem conhecer o produto.

Nesse cenário, a inovação é necessária. Com esse objetivo, em 2013 Mariana foi à Itália e à Espanha buscar produtos diferenciados e novidades no segmento. Visitou fábricas de produtos similares, bem como fabricantes de equipamentos. E encontrou inovações no formato, o que atenderia às demandas de arquitetos por tamanhos diferenciados, e no 
acabamento, o que geraria menos custos de manutenção para clientes, porém nada em termos de novas tecnologias na fabricação e no produto em si. Mariana entende que "o grande desafio é a inovação", e a empresa deve "ficar de olho no que mercado oferece, porque os arquitetos criam tendências. Mas nós só conseguimos achar inovações no formato, e não na nossa atividade, no vibro prensado, no piso cimentício".

Entretanto, Mariana pondera o quanto vale a pena investir em novos formatos de piso, tendo em vista a necessidade de aumentar a produtividade e manter a excelência do sistema da empresa. Mesmo angustiada com esse dilema, e acreditando não ser o melhor momento, Mariana percebe a demanda do mercado. Dessa forma, a Tecnogran planeja investir em novas opções de formatos em um futuro próximo. Demonstrando a importância da inovação para a empresa, Antônio afirma que "a Tecnogran, mesmo em um setor com poucas possibilidades de inovação, procura atuar de forma preventiva, antevendo e observando as tendências mundiais de seu mercado".

Em relação ao problema de manutenção do carro-chefe da empresa, o piso vibro prensado destinado para áreas internas, a Tecnogran também deve tomar outra decisão difícil. O processo de conservação do piso vibro prensado é diferente dos demais tipos de pisos. A Tecnogran entrega o produto em perfeitas condições de uso, mas, o cliente tem que cumprir etapas periódicas de manutenção. Se o padrão não for seguido rigorosamente, a correção acaba ficando muito cara. Devido à dificuldade de conseguir mão de obra especializada nesse tipo de piso, muitos clientes contratam firmas terceirizadas, mas o custo é elevado.

Nesse contexto, a Tecnogran desenvolveu um processo de finalização do piso com um selador desenvolvido por uma indústria química parceira, mais vantajoso em termos de custo e praticidade. Porém, essa solução ainda está em teste e, se der certo, a manutenção será mais simples e barata, desonerando o cliente. Isso colocará a Tecnogran mais uma vez na frente dos concorrentes. Entretanto, a empresa tem que definir por quanto tempo irá testar o produto.

Diante desse cenário, Antônio está apreensivo: se a empresa demorar a fornecer essa solução para os clientes, poderá perder mercado. Por outro lado, se o produto novo apresentar problemas após a aplicação, a empresa terá custos ao reaplicar tratamentos para manter a garantia de fábrica oferecida nas obras. Portanto, este é o novo dilema que a Tecnogran terá que enfrentar e resolver.

\section{ANEXO 1 - NOTAS DE ENSINO}

\section{Fontes de dados}


Este caso de ensino foi elaborado com dados, empresas e personagens reais. Os dados foram obtidos por meio de entrevistas semiestruturadas com gestores da Tecnogran, em novembro de 2014. Outras informações foram obtidas em sites e análises de documentos das empresas e informações de mercado do setor. Os nomes dos personagens são fictícios.

\section{Aspectos pedagógicos}

Este caso de ensino poderá ser utilizado nas disciplinas de Administração Estratégica, Gestão da Inovação, Marketing e disciplinas correlatas, em cursos de graduação e pósgraduação com foco em negócios de empresas. São passos para trabalhar o caso em aula:

$1^{\mathrm{a}}$ etapa: leitura individual;

$2^{a}$ etapa: discussão em grupos;

$3^{\text {a }}$ etapa: discussão entre grupos com moderação do professor;

$4^{\text {a }}$ etapa: considerações do professor sobre o caso e sua importância à luz de teorias escolhidas.

\section{Objetivos educacionais}

- Sensibilizar alunos para perceber as estratégias empresariais;

- Analisar os modelos de gestão em busca de vantagem competitiva;

- Identificar modelos estratégicos organizacionais;

- Relacionar competências organizacionais e vantagem competitiva sustentável;

- Compreender a importância e os desafios da inovação para as organizações.

\section{Perguntas para discussão do caso:}

1. A Tecnogran oferece solução completa ao cliente, com mão de obra especializada que agrega qualidade, porém dificulta a competição por preço. Esse posicionamento é sustentável, considerando a pressão de clientes por preços menores?

2. Quais são as competências da empresa? Elas são compatíveis com cenário da competição no setor?

3. Ao atuar em um mercado com pouco espaço para inovação, a empresa pode ficar estagnada. Que tipo de estratégia a empresa deveria adotar neste contexto para inovar com competitividade?

\section{Alternativas para análise do caso}

$\mathrm{O}$ caso pode ser analisado pelas seguintes perspectivas: Estratégias Genéricas, Tipologias de Estratégia e Vantagem Competitiva Ambiental; Teoria Baseada em Recursos; e Teoria de Recursos, Processos e Valores na Inovação.

\section{=> Estratégias Genéricas e Vantagem Competitiva Ambiental}

O caso pode ser analisado sob a teoria das estratégias genéricas de Porter (1980; 1985), na qual a empresa tem melhor desempenho se conseguir aplicar uma das três estratégias: (1) liderança no custo total, (2) diferenciação e (3) enfoque.

A primeira das estratégias genéricas é a de liderança em custo. Nela a empresa ambiciona transformar-se na produtora de menor custo em seu setor. A vantagem em custo depende da estrutura do mercado. Para isso, a empresa busca economia de escala, propriedade tecnológica, acesso preferencial a matérias-primas, e baixo custo de mão de obra, entre outros fatores.

Na estratégia de diferenciação, a empresa tem por objetivo ser única na sua indústria, ao longo de dimensões que são valorizadas pelos compradores. A empresa seleciona um ou mais atributos percebidos como importantes pelos clientes e posiciona-se de forma exclusiva para atender tais necessidades, sendo recompensada pela sua singularidade com um preço premium. A diferenciação pode ser baseada no produto em si, no sistema de entrega, no direcionamento de marketing e em vários outros fatores (PORTER, 1985).

A estratégia de enfoque pressupõe que a empresa selecione um segmento ou grupo de segmentos na indústria, e oriente a sua estratégia para atendê-los, em detrimento de outros. $\mathrm{O}$ 
enfoque procura alcançar a vantagem competitiva no segmento-alvo, mesmo que não possua vantagem estratégica global (PORTER, 1985).

A figura 3 demonstra as diferenças genéricas que podem levar à vantagem competitiva.

\begin{tabular}{|c|c|c|c|}
\hline \multirow{3}{*}{$\begin{array}{l}\text { ESCOPO } \\
\text { COMPETITIVO }\end{array}$} & \multirow{3}{*}{$\begin{array}{l}\text { Alvo Amplo } \\
\text { Alvo Estreito }\end{array}$} & $\begin{array}{l}\text { VANTAGEM C } \\
\text { Custo Mais Baixo }\end{array}$ & $\begin{array}{l}\text { MPETITIVA } \\
\text { Diferenciação }\end{array}$ \\
\hline & & 1. Liderança em Custo & 2. Diferenciação \\
\hline & & 3A. Enfoque em Custo & $\begin{array}{l}\text { 3B. Enfoque em } \\
\text { Diferenciação }\end{array}$ \\
\hline
\end{tabular}

Figura 3 - Três estratégias genéricas de Porter

Fonte: adaptado de Porter (1985, p. 12).

À luz dessa teoria, a Tecnogran segue a estratégia de diferenciação quanto ao seu produto e ao serviço que agrega - ou, conforme a forma que se olha, um "enfoque em diferenciação", uma vez que se pode considerar o segmento de atuação da empresa como um nicho (piso vibro prensado) dentro de um setor maior (pisos, ou pisos para alto tráfego). Isso possibilita, inclusive, a designação do preço premium por parte da empresa. Seus serviços diferenciados, oferecendo características e atributos distintos dos concorrentes, fazem com que seus clientes valorizem o produto e optem por contratar a Tecnogran mesmo tendo preços elevados. São evidências da diferenciação:

- Oferta completa: a Tecnogran oferece um "sistema para revestimento", e não apenas um produto, pois permite a contratação incluindo serviço de aplicação. Os concorrentes não oferecem serviço de aplicação do revestimento, indicando terceiros para essa atividade. A Tecnogran também conta com arquiteta e setor técnico para o levantamento da planta e adequação da quantidade de piso a ser utilizado, e com o setor de qualidade, que fiscaliza a obra para avaliar o seguimento dos padrões da empresa;

- Inovação: a empresa pesquisa e desenvolve novos pisos, como os drenantes;

- Fidelização do cliente: segmenta o relacionamento com o cliente segundo seu perfil, inclusive criando catálogos com produtos específicos para cada segmento.

- Distribuição / logística: a empresa entrega rapidamente em todo o Brasil e coloca o piso sem interromper a construção;

- Qualidade do produto: adquiriu pedreira própria para garantir a pureza da granilha utilizada em seus pisos; utiliza de mão de obra especializada, possuindo funcionários com ampla experiência no serviço;

- Outros atributos: tempo de mercado, reputação, portfólio de obras realizadas, alta capacidade produtiva e expertise reconhecida.

Entretanto, o argumento de Porter (1985) em favor de estratégias genéricas "puras" é controverso (MILLER, 1992; THORNHILL, WHITE, 2007). Alguns autores questionam sua capacidade de explicar movimentos estratégicos face o atual dinamismo do ambiente de negócios (GOULD; DESJARDINS, 2015). Outros autores reconhecem situações em que estratégias podem ser combinadas (MARKIDES, CHARITOU, 2004). Por exemplo: (a) empresas podem manter negócios com estratégias diferentes em unidades (de negócio, UN) distintas; (b) mudanças tecnológicas ou inovação em gestão podem permitir tanto aumento da qualidade quanto redução de custos; e (c) falhas competitivas no setor (com um dominante no setor ou concorrentes sem posicionamento definido) admitem que empresas sobrevivam confortavelmente sem assumir uma estratégia genérica.

Tais ideias inspiram a resposta à pergunta (1), sobre como a empresa pode sustentar seu posicionamento premium e lidar com pressões por preços menores Por manter toda uma estrutura de soluções completas para revestimento, a Tecnogran não compete em preço. 
Entretanto, a empresa está atenta para a pressão de preços no setor - segundo Porter (1985), um preço premium pode ser anulado por um custo de produção marcadamente inferior. Para evitar esse risco, a empresa pode aproximar seus custos de seus concorrentes em todas as áreas que não afetam a diferenciação. Provavelmente por isso que a Tecnogran sentiu a necessidade de reduzir custos: aumentou a escala de produção, reduziu desperdício, introduziu procedimentos de controle qualidade (como gestão à vista), adquiriu uma mineradora (com vistas tanto a reduzir custos como aumentar a qualidade; neste sentido, entregando a operação a um terceiro para manter custos baixos); contratou empresas de consultoria administrativofinanceira e comercial; e contratou para a fábrica um novo gerente industrial.

\section{$=>$ Teoria Baseada em Recursos}

A Teoria Baseada em Recursos (TBR) tem dois pressupostos básicos: (1) as empresas em um setor podem ser heterogêneas em relação aos seus recursos estratégicos; e (2) esses recursos podem ser não transferíveis (BARNEY, 1991). A noção de que as empresas são fundamentalmente heterogêneas, em termos de seus recursos e capacidades internas, desperta interesse nos estudos sobre gestão estratégica (PETERAF, 1993). Denominada inicialmente de Visão Baseada em Recursos por Wennerfeld (1984), Barney et al (2011), seguindo outros pesquisadores, propuseram que já fosse tratada como teoria, uma vez que a "pesquisa baseada em recursos já atingiu um nível de precisão e sofisticação que a assemelham mais a uma teoria do que a uma visão" (p. 1303).

Há complementariedade entre modelos de vantagem competitiva ambiental (tais como o de Porter) e a TBR. Os modelos ambientais enfatizam oportunidades e ameaças, e como empresas devem se posicionar para enfrentá-las. A TBR examina recursos e suas características que permitem gerar vantagem competitiva sustentável (BARNEY, 1991).

A maior contribuição da TBR é explicar as diferenças de longo prazo na rentabilidade das empresas, que não podem ser atribuídas a diferenças nas condições do setor (PETERAF, 1993). Segundo Barney (1991), as características da empresa só se tornam recursos quando exploram oportunidades ou neutralizam ameaças no ambiente de atuação da empresa, desta forma habilitando-a a conceber e implantar estratégias que melhorem sua eficiência e eficácia.

Os principais conceitos-chave da TBR são: recursos das empresas; vantagem competitiva; e vantagem competitiva sustentável. Vantagem competitiva ocorre quando uma empresa implementa uma estratégia de criação de valor que não é implementada simultaneamente por competidor atual ou potencial. Já vantagem competitiva sustentável ocorre se a empresa implementa uma estratégia de criação de valor não é implementada simultaneamente por competidor atual ou potencial, e quando os competidores não conseguem duplicar os benefícios dessa estratégia. A vantagem competitiva sustentável não significa perpétua, mas sim que não será suplantada pelos esforços de imitação de outras empresas (BARNEY, 1991).

Definir um negócio em termos do que ele é capaz de fazer oferece uma base mais duradoura para a estratégia do que definir com base nas necessidades que a empresa pretende satisfazer (GRANT, 1991). Dierickx e Cool (1989) defendem que o ponto fundamental para formular estratégias consiste em fazer escolhas adequadas sobre gastos estratégicos (publicidade, despesas de $\mathrm{P} \& \mathrm{D}$, etc.), com vistas à acumulação de recursos e habilidades necessários (fidelidade à marca, conhecimento tecnológico, etc.). Em outras palavras, decisões apropriadas em relação ao fluxo de variáveis relevantes devem ser tomadas de forma a edificar estoques de recursos cruciais. Estoques de ativos críticos ou estratégicos são aqueles que são não comercializáveis, não imitáveis e não substituíveis. Desta forma, a busca de vantagem competitiva e de desempenho superior deve começar com uma análise dos recursos e das capacidades que uma empresa tem controle (BARNEY; CLARK, 2007). 
Segundo Grant (1991), se os recursos e as capacidades da empresa têm pouca durabilidade, ou são facilmente transferidos ou replicados, a empresa deverá adotar uma estratégia de obtenção de resultados de curto prazo, ou então deverá investir no desenvolvimento de novas fontes de vantagem competitiva (GRANT, 1991). Visto de outro modo, não é possível obter vantagem competitiva sustentável em setores cujas empresas possuem recursos homogêneos e transferíveis. Sendo assim, a busca por fontes de vantagem competitiva sustentável deve focar na heterogeneidade e intransferibilidade dos recursos (BARNEY, 1991). Barney (1991) argumenta que, para prover vantagem competitiva sustentável, os recursos devem ser valiosos, raros, não substituíveis e não imitáveis. Estes atributos sinalizam o quão heterogêneos e imóveis os recursos são, e, portanto, o quanto tais recursos ajudam a gerar vantagens competitivas sustentáveis (BARNEY; CLARK, 2007).

Para Barney (1991), um recurso é valioso quando permite à empresa elaborar ou implementar estratégias que aumentem sua eficiência e eficácia, e, assim, criar valor. Um recurso é raro quando poucos competidores o possuem. É não substituível quando não há recursos estrategicamente equivalentes disponíveis para os concorrentes (similares ou diferentes). E, por fim, é não imitável quando competidores que não possuem o recurso não conseguem obtê-lo. Isso pode ocorrer por três motivos: (1) por condições históricas únicas, que determinam o caminho que a empresa percorreu para chegar aonde chegou (path dependency ou dependência de trajetória); (2) por ambiguidade de causas, que ocorre quando os recursos da empresa estão ligados de uma forma que não é compreendida perfeitamente; e (3) por complexidade social, tais como as relações interpessoais entre gerentes, cultura da empresa, reputação entre clientes e fornecedores, etc. (BARNEY, 1991).

Posteriormente, Barney e Clark (2007) incluem mais um atributo para um recurso ter potencial vantagem competitiva sustentável: ser capaz de ser explorado pelos processos organizacionais da empresa. Recursos valiosos, raros, e imitáveis só podem ser fonte de vantagem competitiva sustentável se a empresa está organizada para explorar seu potencial. Processos organizacionais fornecem mais uma condição necessária para a realização da vantagem competitiva sustentável.

Desenvolvimentos posteriores da TBR levaram à elaboração do conceito de competências organizacionais, entendidos como articulação de recursos que provém à organização desempenho superior em um fator chave de sucesso ao setor (MILLS et al, 2003; FERNANDES, 2013). A noção de competências organizacionais implica que dificilmente recursos individuais sustentam uma vantagem competitiva: quando entrelaçados é que se tornam valiosos, difíceis de imitar ou substituir.

Barney (1991) divide os recursos das empresas em três categorias: (1) capital físico tecnologia, máquinas e equipamentos, localização geográfica e acesso a matérias-primas; (2) capital humano - treinamento, experiência, expertise, inteligência, relacionamentos, insights, capacidade de julgamento e tomada de decisão dos indivíduos da empresa; e (3) capital organizacional - estrutura formal, planejamento formal e informal, sistemas de controle e coordenação entre grupos dentro da empresa e entre empresa e ambiente.

Em que pesem as críticas dirigidas à TBR sobre tautologia e imprecisão nos seus constructos (WILLIANSON, 1999; PRIEM, BUTLER, 2001), ou mesmo sua dificuldade em lidar com a volatilidade do ambiente de negócios e rápido desenvolvimento de capacidades dinâmicas (TEECE et al, 1997; ACAR, POLIN, 2015), Barney (2001) sugere que tais argumentos são válidos em estudos cujas variáveis foram mal operacionalizadas, e que desenvolvimentos posteriores da teoria evidenciam poder explicativo significativo em temas de administração estratégica.

À luz da TBR, considerando a pergunta (2) sobre competências organizacionais da Tecnogran, estão relacionadas ao domínio da tecnologia e soluções para fabricação, 
instalação e manutenção de pisos de alto tráfego. Trata-se de uma competência valiosa, rara, difícil de imitar e substituir, e provê acesso a mercados diversos (MILLS et al, 2003).

A competência é valiosa, dado que a empresa tem o maior parque industrial entre os concorrentes, o que permite ganhos de escala. Está localizada em uma região de fácil acesso a fornecedores de matérias-primas essenciais ao processo. É proprietária de pedreira com pedras de elevada pureza. Ainda, domina tecnologias produtivas e relativas à prestação de serviços de instalação e manutenção de pisos.

A raridade da competência manifesta-se principalmente no fato de que é a única no setor que vende "pacotes completos", isto é, o produto pronto e instalado. Além disso, possui uma pedreira com pedras de alta qualidade e pureza.

A competência é de difícil substituição. De fato, sem dominar tecnologias e prover soluções para instalação e manutenção de pisos, como competir neste setor? Difícil encontrar substitutos estratégicos similares. Atenção, porém, deve ser dada a produtos substitutos, como pisos de granito, porcelanato, pavers e concreto. À medida que (e se) reduzirem custos por força de produtividade, ou melhorarem sua qualidade e acabamento, podem representar potenciais substitutos à parte da oferta da empresa.

A competência também é não imitável. Sua expertise no setor deriva de uma experiência acumulada (dependência de trajetória) e da combinação de recursos que é difícil replicar em sua integralidade: a propriedade da pedreira; a reputação da marca associada ao setor; o portfolio de projetos desenvolvidos; a carteira de clientes; a expertise do seu quadro funcional oriunda de anos de experiência trabalhando conjuntamente, com vínculos familiares e morando nas proximidades da fábrica, entre outros. Tais fatores interagem, gerando uma complexidade social de difícil imitação pelos concorrentes.

A competência também é passível de exploração pelos processos organizacionais. Observa-se que a empresa explora e integra sua expertise para gerar novos produtos e serviços (como a própria aplicação dos pisos) e melhorar processos. Por fim, a competência provê acesso a novos mercados. Ainda que de forma limitada, o fato de a empresa dominar tecnologias e soluções em pisos a permitiu ofertar serviços de aplicação e manutenção e entrar em novos mercados, como setor público, mercados residenciais, entre outros.

Tal competência parece posicionar a empresa de forma competitiva ao novo cenário do setor. É verdade que a Tecnogran deve acompanhar as mudanças de perto, sobretudo as exigências de pisos em novos formatos pelos compradores, e a pressão por preços. Porém, a empresa demostra estar agindo em face de tais situações, monitorando novidades no setor e desejos dos compradores, e implementando melhorias em processos. Ainda não parecem ocorrer inovações disruptivas que afetem o setor e que venham a fragilizar a atuação da empresa. Isto posto, pode se afirmar que a vantagem competitiva da Tecnogran é sustentável.

\section{$\Rightarrow$ Teoria de Recursos, Processos e Valores na Inovação}

Christensen e Raynor (2003) observam que muitas inovações falham por falta de capacidade das organizações em desenvolvê-las. As capacidades de uma organização tornamse suas deficiências quando uma disrupção acontece. Os autores dividem o conceito de capacidade em três classes de fatores que definem o que uma organização pode ou não realizar: recursos, processos e valores, formando uma tríade denominada modelo RPV (CHRISTENSEN; RAYNOR, 2003).

Esta teoria deriva da constatação que empresas tendem a sofrer dificuldades ao enfrentar inovações disruptivas - aquelas que mudam o conceito de utilização de um produto ou provocam ruptura no mercado (DAVILA; EPSTEIN; SHELTON, 2007). A disrupção tem efeito paralisante sobre líderes da indústria. Empresas líderes tem foco em inovações sustentadoras ou incrementais, que consistem na otimização de produtos e processos existentes, de modo a extrair o máximo valor possível sem necessidade de grandes mudanças 
ou investimentos. Leva a melhorias moderadas nos produtos e processos dos negócios em vigor (DAVILA; EPSTEIN; SHELTON, 2007). Os líderes têm dificuldade para responder a inovações disruptivas, pois seus valores, processos e recursos são direcionados para aproveitar principalmente inovações sustentadoras (CHRISTENSEN; RAYNOR, 2003).

No tocante à inovação em produtos e serviços, é possível relacionar a estratégia da Tecnogran com a Teoria de Recursos, Processos e Valores (RPV) de Christensen e Raynor (2003). O modelo RPV pode ser útil para executivos determinarem o que precisam para criar novas capacidades, porque aquelas que suas organizações têm atualmente não necessariamente são adequadas para construir novos negócios e crescer.

As ideias precedentes ajudam a responder à questão (3), sobre que tipo de estratégia a Tecnogran pode adotar para poder inovar com competitividade. A Tecnogran é líder em seu segmento e, como tal, aperfeiçoou recursos, processos e valores que a predispõe a gerar inovações sustentadoras, o que foi evidenciado no desenvolvimento de seu modelo de negócios ampliado, com foco em serviços e a busca recente de melhoria em produtividade para reduzir custos. Para não descolar-se de tendências e inovações no setor, a empresa realiza viagens de benchmarking, visita concorrentes e fornecedores, sem encontrar tecnologias disruptivas que a ameacem. Busca oportunidades de diversificação, inclusive inovando por meio de parcerias, como no caso de pisos drenantes.

Em síntese, os esforços da empresa devem se manter na consolidação da inovação sustentadora (ampliando os serviços, estendendo seu portfolio com pequenas adaptações a novos mercados, melhorando processos), dada sua liderança, e ao mesmo tempo direcionar-se à busca de conhecimentos externos (atentando que já possui suficiente conhecimento instalado, que para Cohen e Levinthal [1990] é um pressuposto para a capacidade de absorção) para não perder o compasso de possíveis mudanças disruptivas em seu setor. A empresa investe energia nas duas frentes. No segundo campo, inclusive, mantendo parcerias com empresas de outro setor, como no caso do desenvolvimento dos pisos drenantes. A seu favor, está o fato de não existir (aparentemente) transformações disruptivas em curso neste setor.

\section{REFERÊNCIAS}

ACAR, W.; POLIN, B. The ascent of resource-based theory as constructive rationalbehavioral integration for looking inward and outward. International Journal of Commerce \& Management, Bingley, v. 25, n. 4, p. 603-626, 2015.

BARNEY, J. Firm Resources and Sustained Competitive Advantage. Journal of Management, Thousand Oaks, v. 17, n. 1, 1991.

BARNEY, J. B. Is the resource-based "view" a useful perspective for strategic management research? Yes. Academy of Management Review, Briarcliff Manor, v. 26, n. 1, p. 41-56, 2001.

BARNEY, J. B.; CLARK, D. N. Resource-Based Theory: Creating and Sustaining Competitive Advantage. UK: Oxford University Press, 2007.

BARNEY, J.; KETCHEN, D.; WRIGHT, M. The Future of Resource-Based Theory: Revitalization or Decline? Journal of Management,Thousand Oaks, v. 37, n. 5, p. 12991315, Sept. 2011. 
CHRISTENSEN, C. M.; RAYNOR, M. E. The Innovator's Solution: Creating and Sustaining Successful Growth. Boston: Harvard Business School Publishing, 2003.

COHEN, W.; LEVINTHAL, D. Absorptive Capacity: A New Perspective on Learning and Innovation. Administrative Science Quarterly, Thousand Oaks, v. 35, p. 128-152, 1990.

DAVILA, T.; EPSTEIN, M. J.; SHELTON, R. D. As regras da Inovação. Porto Alegre: Bookman, 2007.

DIERICKX, I.; COOL, K. Asset Stock Accumulation and Sustainability of Competitive Advantage. Management Science, Catonsville, v. 35, n. 12, p. 1504-1511, December, 1989.

FERNANDES, B. H. R. Gestão Estratégica de Pessoas com foco em competências. Ed. Campus: Rio de Janeiro, 2013.

GRANT, R. M. The Resource-Based Theory of Competitive Advantage: Implications for Strategy Formulation. California Management Review, Thousand Oaks, p. 114-135, Spring, 1991.

MARKIDES, C.; CHARITOU, C. Competing with dual business models: a contingency approach. Academy of Management Executive, [s.1.], v. 18, p. 22-36, 2004.

MILLER, D. The generic strategy trap. Journal of Business Strategy, Bingley, v. 13, p. 3742, 1992.

MILLS, J.; PLATTS, K.; BOURNE, M. Competence and resource architectures.

International Journal of Operations \& Production Management, Bingley, v. 23, n. 9, p. 977-994, 2003.

GOULD, A. M.; DESJARDINS, G. Competitiveness Review. "A spring-clean of Michael Porter's Attic: The Canadian telecommunications sector as an exemplar of refurbished generic strategy". Competitiveness Review, Bingley, v. 25, n. 3, p.310-323, 2015.

PETERAF, M. A. The Cornerstones of Competitive Advantage: a Resource-Based View. Strategic Management Journal, Hoboken, v. 14, p. 179-191, 1993.

PORTER, M. E. Competitive strategy: techniques for analysing industries and competitors. New York: Free Press, 1980.

PORTER, M. E. Competitive advantage: creating and sustaining competitive performance. New York: Free Press, 1985.

PRIEM, R. L.; BUTLER, J. E. Is the Resource-Based "View" a useful perspective for strategic management research? Academy of Management Review, Briarcliff Manor, v.26, n.1, p. 22-40, 2001

TEECE, D. J.; PISANO, G.; SHUEN, A. (1997). Dynamic capabilities and strategic management. Strategic Management Journal, Hoboken, v. 18, n. 7, p. 509-533, 1997. 
THORHILL, S.; WHITE, R. Strategy purity: a multi-industry evaluation of pure vs hybrid business strategies. Strategic Management Journal, Hoboken, v. 28, p. 553-561, 2007

WENERFELT, B. A Resource Based View of the Firm. Strategic Management Journal, Hoboken, p. 171-180, April-June, 1984.

WILLIANSON, Oliver E. Strategy research: governance and competence perspectives. Strategic Management Journal, Hoboken, v. 20, n. 12, p.1087-1108, December, 1999. 